\title{
Sequence analysis of peste des petits ruminants virus from ibexes in Xinjiang, China
}

\author{
J. Xia ${ }^{1}$, X.G. Zheng ${ }^{2}$, G.Z. Adili ${ }^{3}$, Y.R. Wei ${ }^{1}$, W.G. Ma ${ }^{1}$, X.M. Xue ${ }^{4}$, \\ X.Y. Mi ${ }^{1}$, Z. Yi ${ }^{1}$, S.J. Chen ${ }^{1}$, W. Du ${ }^{1}$, M. Muhan ${ }^{3}$, C. Duhaxi ${ }^{1}$, \\ T. Han' ${ }^{1}$, B. Gudai ${ }^{5}$ and J. Huang ${ }^{1}$ \\ ${ }^{1}$ Institute of Veterinary Medicine, Xinjiang Academy of Animal Science, \\ Urumqi, Xinjiang, China \\ ${ }^{2}$ China Animal Health and Epidemiology Center, Qingdao, Shandong, China \\ ${ }^{3}$ The Wildlife Epidemics and Epidemic Sources Monitoring Center of \\ Xinjiang Uyghur Autonomous Region, Urumqi, Xinjiang, China \\ ${ }^{4}$ The Center for Animal Disease Control and Prevention of Byingol \\ Mongol Autonomous Prefecture, Korla, Xinjiang, China \\ ${ }^{5}$ The Institution for Wildlife Conservation of Bazhou, Korla, Xinjiang, China \\ Corresponding author: J. Huang \\ E-mail: huangjh_2015@126.com
}

Genet. Mol. Res. 15 (2): gmr.15027783

Received October 6, 2015

Accepted November 23, 2015

Published June 3, 2016

DOI http://dx.doi.org/10.4238/gmr.15027783

\begin{abstract}
Peste des petits ruminants (PPR) is an infectious disease caused by peste des petits ruminants virus (PPRV). While PPR mainly affects domestic goats and sheep, it also affects wild ungulates such as ibex, blue sheep, and gazelle, although there are few reports regarding PPRV infection in wild animals. Between January 2015 and February 2015, it was found for the first time that wild ibexes died from PPRV infection in Bazhou, Xinjiang, China, where a total of 38 ibexes (including young and adult ibexes) were found to have died abnormally from PPR-related issues. First, we tested for the presence of the F gene of PPRV by RT-PCR. Then, we compared the sequence of the isolated $\mathrm{F}$ gene from the ibex strain, termed PPRV Xinjiang/Ibex/2015, with those previously identified from small domestic ruminants from local areas
\end{abstract}


near where the reported isolate was collected as well as those from other regions. The current sequence was phylogenetically classified as a lineage IV virus, and shared a high level of sequence identity $(99.7 \%)$ with a previously described Xinjiang PPRV isolate.

Key words: Peste des petits ruminants; Ibex; Xinjiang

\section{INTRODUCTION}

Peste des petits ruminants (PPR) is an endemic viral disease affecting sheep and goats across many areas of Africa, the Middle East, and Asia, and is caused by peste des petits ruminants virus (PPRV) (Govindarajan et al., 1997). PPR is categorized as a Food and Agriculture Organization of the United Nations and World Organization for Animal Health (FAO/OIE) grade A severe contagious disease, with an incidence and mortality rate as high as 100 and $90 \%$, respectively (Zhu et al., 2009). Additionally, PPR is classified as a firstclass animal contagious disease in China (Zhu et al., 2009). PPRV is a negative-sense, singlestranded RNA virus of the genus Morbillivirus, which is genetically grouped into four lineages (I, II, III, and IV) based on partial sequence analysis of the fusion (F) gene, of which lineages I to III circulate in Africa and lineage IV in Asia (Dhar et al., 2002). There are six structural PPRV proteins that are encoded by 6 genes, namely N-P-M-F-H-I in that order from the 3'to the 5'-terminus of the viral genome (Bailey et al., 2005). The F protein is a fusion protein that is important for successful viral infection. Specifically, the spikes on the viral envelop surface are comprised of the F protein, and are associated with viral adherence and invasion (Muthuchelvan et al., 2006), which are crucial steps for successful infection (Haffar et al., 1999; Jing et al., 2004). PPR was first reported in West Africa in 1940, and is now mainly present in Africa, the Middle East, the Arabian Peninsula, and South Asia (Özkul et al., 2002).

In July 2007, a PPR outbreak was reported in the Ngari region of southwestern Tibet, China (Wang et al., 2009). In December 2013, a new outbreak of PPR was reported in Xinjiang Province, and PPR was also detected in Gansu, Inner Mongolia, Ningxia, Jiangxi, and Hunan Provinces by mid-March 2014 (Wang et al., 2015). The ibex, also known as the Asian antelope, is under First-Grade State Protection in China, and primarily lives in groups distributed among the Xinjiang Tianshan Mountains, northwestern Gansu Province, and the northwestern Inner Mongolia Autonomous Region. Therefore, the aim of the current study was to compare the sequences of the F gene of PPRV infecting ibexes in Xinjiang, China, with other PPRV sequences available in the GenBank database in order to improve our knowledge of the epidemiology of PPR in the country.

\section{MATERIAL AND METHODS}

\section{Specimen collection}

The Bazhou region is approximately $500 \mathrm{~km}$ away from Urumqi, the capital of Xinjiang Province in northwest China. The region is home to a wide range of wild animals including ibex, argali, wild yak, deer, brown bear, and snow leopard. A total of 38 wild ibexes died abnormally in the Bazhou region from January to February 2015. The cause of death seemed to be PPR according to the clinical signs and symptoms. As such, the Xinjiang Academy of 
Animal Science cooperated with the China Animal Health and Epidemiology Center to further investigate the mortalities of ibexes in this region. Lungs, lymph nodes, and swab samples were collected from suspected PPRV-infected ibexes, all of which showed typical symptoms of PPR, including fever, lassitude, anorexia, and diarrhea. Clinical tissues were homogenized for RNA extraction, and the remaining samples were kept at $-20^{\circ} \mathrm{C}$ until further use.

\section{Viral genomic RNA extraction}

Homogenized tissue slurry $(200 \mu \mathrm{L})$ was mixed with $1 \mathrm{~mL}$ TRIzol reagent (Thermo Fisher, Carlsbad, CA, USA) and incubated at room temperature for 6-10 min. Then, 200 $\mu \mathrm{L}$ chloroform was added and the solution was incubated for $10 \mathrm{~min}$. The mixture was then centrifuged at 12,000 rpm for $20 \mathrm{~min}$ and the supernatant was discarded. The pellet was washed with $75 \%$ ethanol (v/v), dried at $37^{\circ} \mathrm{C}$ for 5-10 min, diluted in $20 \mu \mathrm{L}$ DEPC water, and stored at $-20^{\circ} \mathrm{C}$ until later use.

\section{Reverse transcription-polymerase chain reaction (RT-PCR) amplification of the target gene}

The following primers were designed using the Oligo 6.0 software (Molecular Biology Insights, Cascade, CO, USA) for target F gene amplification based on the genome sequence of PPRV Nigeria 75/1 strain available in the National Institutes of Health (NIH) National Center for Biotechnology Information (NCBI) GenBank: P1, 5'-ATGCTCTGTCGGTGATAAC-3' and P2, 5'-TCGCATGACATTCTATGAAC-3'. The anticipated length of the amplified product was 322 bp. The SuperScript I One-Step RT-PCR Platinum Taq HiFi System (Invitrogen, Carlsbad, CA, USA) reaction mixtures consisted of $3 \mu \mathrm{L}$ total RNA, $25 \mu \mathrm{L}$ Reaction Mix, 5 $\mu \mathrm{L}$ dNTPs, $3 \mu \mathrm{L}$ primers, $1 \mu \mathrm{L}$ RT/Platinum Taq, and $13 \mu \mathrm{L}$ RNase Free $\mathrm{ddH}_{2} \mathrm{O}$. The cycling conditions for target $\mathrm{F}$ gene amplification were as follows: 1 cycle of RT $\left(50^{\circ} \mathrm{C}\right.$ for $30 \mathrm{~min}$, and $94^{\circ} \mathrm{C}$ for $\left.2 \mathrm{~min}\right)$; followed by 30 cycles of PCR including denaturation $\left(94^{\circ} \mathrm{C}\right.$ for $\left.30 \mathrm{~s}\right)$, annealing $\left(56^{\circ} \mathrm{C}\right.$ for $\left.30 \mathrm{~s}\right)$, and extension $\left(72^{\circ} \mathrm{C}\right.$ for $\left.1 \mathrm{~m}\right)$; and then a final extension at $72^{\circ} \mathrm{C}$ for $10 \mathrm{~min}$.

\section{Target gene cloning and sequencing}

The RT-PCR products were purified using a DNA gel extraction kit (Bioteck, Beijing, China) following the manufacturer protocol. The purified products were inserted into the pMD18-T vector and transformed into HD5 $\alpha$ cells. The transformed cells were screened, the plasmid was extracted, and the target gene was detected using $1 \%$ agarose gel electrophoresis following PCR. The screened positive clones were then sent to Shanghai Bioengineering Co. Ltd. (Shanghai, China) for sequencing. All data were processed and analyzed with the DNASTAR software (Lasergene, Madison, WI, USA).

\section{RESULTS}

\section{RT-PCR F gene amplification}

The RT-PCR amplification product of the Xinjiang/Ibex/2015 strain F gene was 
detected by $1 \%$ agarose gel electrophoresis. The results showed that the size of the amplified fragment was consistent with that of the anticipated product, and was approximately $322 \mathrm{bp}$ (Figure 1).

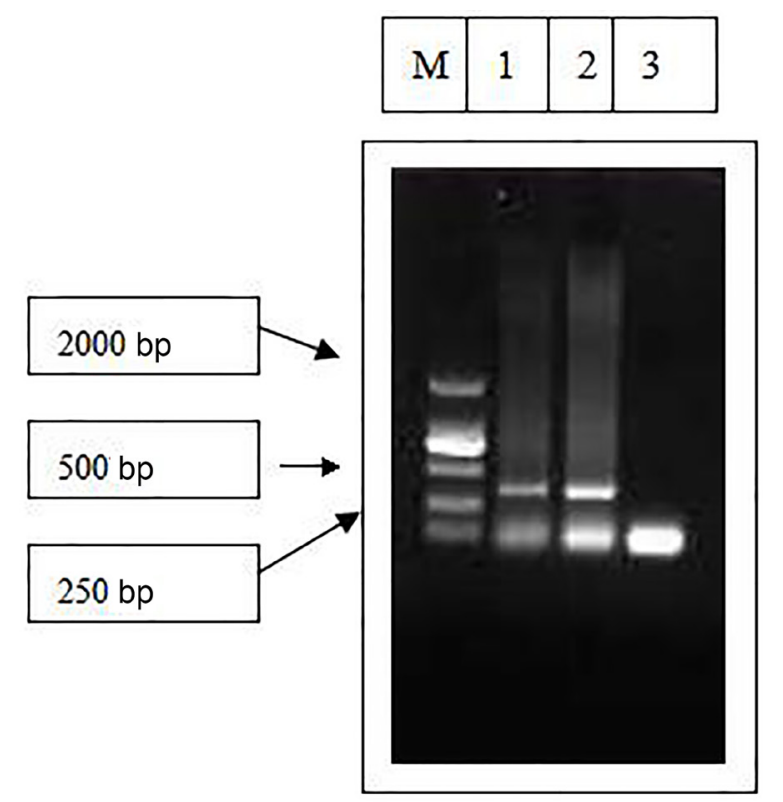

Figure 1. RT-PCR products following F gene amplification and 1\% agarose gel electrophoresis. Lane M= DL2000 bp; lane 1 = sample 1 ; lane 2 = sample 2 ; lane $3=$ control.

\section{F gene sequencing}

The sequencing results showed that the size of the amplified $\mathrm{F}$ gene product from the Xinjiang/Ibex/2015 strain was $322 \mathrm{bp}$, and had the following sequence: ATGCTCTGTCGGTGATAACCAAGAATGTAAGACCAATTCAAACTCTAACACCTGGG CGTAGAACCCGCCGTTTTGCTGGAGCTGTTCTGGCCGGGGTAGCACTTGGAGTT GCGACAGCCGCTCAGATAACTGCAGGAGCCGCCCTTCATCAATCATTGATGAAC TCCCAAGCAATTGAGAGTTTAAAAACCAGTCTTGAGATGTCGAATCAGGCAATA GAAGAAATCAGACTTGCAAATAAGGAGACCATACTGGCAGTACAGGGCGTCCA GGATTATATCAACAATGAGCTCGTCCCTTCTGTTCATAGAATGTCATGCGA.

\section{F gene homology analysis}

Gene homology analysis revealed that the nucleotide sequence homology between the PPRV Xinjiang/Ibex/2015 F gene and domestic and foreign reference strain $\mathrm{F}$ genes was $88.5-99.7 \%$, with the lowest sequence homology $(88.5 \%)$ to that of the $\mathrm{F}$ gene of the Yemen_2001b strain, and the highest sequence homology (up to 99.7\%) to those of the domestic separated strains China/XJYL/2013, China/Shaanxi/2014, and China/Beijing/2014 (Figure 2). 


\begin{tabular}{|c|c|c|c|c|c|c|c|c|c|c|c|c|c|c|c|c|c|c|c|c|c|c|c|c|c|c|}
\hline \multicolumn{27}{|c|}{ Percent Identity } \\
\hline \multirow{25}{*}{ 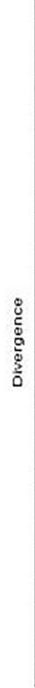 } & & 1 & 2 & 3 & 4 & 5 & 6 & 7 & 8 & 9 & 10 & 11 & 12 & 13 & 14 & 15 & 16 & 17 & 18 & 19 & 20 & 21 & 22 & 23 & & \multirow{2}{*}{ Nepal 2009} \\
\hline & 1 & & 96.6 & 98.4 & 97.8 & 99.1 & 99.1 & 90.7 & 97.2 & 98.1 & 89.1 & 95.0 & 98.4 & 97.5 & 97.5 & 97.8 & 88.5 & 93.2 & 99.1 & 97.8 & 97.25 & 97.89 & 97.89 & 97.5 & 1 & \\
\hline & 2 & 3.5 & & 96.9 & 97.5 & 97.5 & 96.3 & 89.8 & 97.5 & 97.8 & 88.2 & 94.7 & 96.9 & 97.2 & 97.2 & 97.5 & 882 & 91.9 & 96.9 & 96.3 & $95.7 \mathrm{~s} x-2$ & 96.39 & 96.39 & 96.0 & 2 & Irзq 2002 \\
\hline & 3 & 1.6 & 3.2 & & 98.1 & 99.4 & 98.1 & 91.3 & 97.5 & 98.4 & 89.8 & 95.3 & 98.8 & 97.8. & 97.8 & 98.1 & 89.1. & 93.8 & 98.1 & 99.4 & 98.8 & 99.49 & $99.4 \subseteq-4 x$ & 99.1 & 3 & R22 10 \\
\hline & 4 & 22 & 2.5 & 1.9 & & 98.8 & 97.5 & 90.7 & 98.1 & 99.1 & 89.1 & 96.0 & 98.1 & 98.4 & 98.4 & 98.8 & 89.1 & 93.2. & 97.5 & 97.5 & 96.95 & 97.59 & 97.59 & 97.2 & 4 & Mon 96 \\
\hline & 5 & 0.9 & 2.5 & 0.6 & 1.3 & & 98.8 & 91.3 & 98.1 & 99.1 & 89.8 & 96.0 & 99.4 & 98.4 & 98.4 & 98.8 & 89.1 & 93.8 & 98.8 & 98.8 & 98.19 & $98.89-x-8$ & $98.89-2 x$ & 98.4 & 5 & $\operatorname{Koch} 2000$ \\
\hline & 6 & 0.9 & 3.8 & 1.9 & 2.5 & 1.3 & & 90.4 & 96.9 & 97.8 & 88.8 & 94.7 & 98.1 & 97.2 & 97.2. & 97.5 & 88.2 & 92.9 & 98.8 & 97.5 & 96.95 & 97.59 & 97.59 & 97.2 & 6 & Bsk Gujj 05 \\
\hline & 7 & 10.1 & 11.2 & 9.4 & 10.1 & 9.4 & 10.5 & & 90.1 & 91.3 & 97.8 & 90.1 & 91.3 & 91.0 & 90.4 & 90.7. & 97.5 & 91.9 & 90.4 & 91.0 & 90.7 & 91.09 & 91.09 & 90.7 & 7 & Gedani KSUD71 \\
\hline & 8 & 2.9 & 25 & 25 & 1.9 & 1.9 & 3.2 & 10.9 & & 98.4 & 88.5 & 95.3 & 97.5 & 97.8 & 97.8 & 98.1 & 88.5 & 92.5 & 96.9 & 96.9 & 96.35 & $96.99-x-29$ & $96.99-2 x-2$ & 96.6 & 8 & Egyp 1112009 \\
\hline & 9 & 1.9 & 22 & 1.6 & 0.9 & 0.9 & 2.2 & 9.4 & 1.6 & & 89.8 & 96.6 & 98.4 & 98.8 & 98.8 & 99.1 & 89.8 & 93.8 & 97.8 & 97.8 & 97.25 & $97.89-20$ & $97.89-2 x-3$ & 97.5 & 9 & TamilNadu 2011 \\
\hline & 10 & 10.7 & 11.8 & 9.9 & 10.7 & 9.9 & 11.1 & 1.0 & 11.5 & 9.9 & & 88.2 & 89.8 & 89.4 & 88.8 & 89.1 & 96.0 & 90.1 & 88.8 & 89.4 & 89.4 & 89.48 & 89.48 & 89.1 & 10 & sudan 1972 seq \\
\hline & 11 & 5.2 & 5.5 & 4.8 & 42 & 4.2 & 5.5 & 10.9 & 4.9 & 3.5 & 11.8 & & 95.3 & 95.7 & 95.7. & 96.0 & 88.5 & 932. & 94.7 & 94.7 & 94.19 & 94.79 & 94.79 & 94.4 & 11 & Soba Khartoum KHSUDO8 \\
\hline & 12 & 1.6 & 3.2 & 1.3 & 1.9 & 0.6 & 1.9 & 9.4 & 25 & 1.6 & 9.9 & 4.9 & & 97.8 & 97.8 & 98.1 & 89.1 & 93.2 & 98.1 & 98.1 & 97.59 & 98.19 & 98.19 & 97.8 & 12 & Pakistan 2009 \\
\hline & 13 & 25 & 2.9 & 22 & 1.6 & 1.6 & 2.9 & 9.8 & 22 & 1.3 & 10.3 & 45 & 22 & & 98.1 & 98.4 & 90.1 & 93.5 & 97.2 & 972 & 96.65 & $97.29-2 x-2$ & 97.29 & 96.9 & 13 & Morocoso 08.9 \\
\hline & 14 & 25 & 2.9 & 22 & 1.6 & 1.6 & 2.9 & 10.5 & 22 & 1.3 & 11.1 & 4.5 & 22 & 1.9 & & 98.4 & 88.8 & 92.9 & 97.2 & 97.2 & 96.65 & $97.29-29$ & $97.2 s-x-2$ & 96.9 & 14 & Meh Guj 05 \\
\hline & 15 & 22 & 2.5 & 1.9 & 1.3 & 1.3 & 2.5 & 10.1 & 1.9 & 0.9 & 10.6 & 42 & 1.9 & 1.6 & 1.6 & & 89.1 & 932. & 97.5 & 97.5 & $96.99-9$ & 97.59 & 97.59 & 97.2 & 15 & Kuwati 1999 \\
\hline & 16 & 12.8 & 13.1 & 12.0 & 12.1 & 12.1 & 13.2 & 2.5 & 12.8 & 11.3 & 2.9 & 12.8 & 12.1 & 10.9 & 12.5 & 12.0 & & 90.4 & 88.2 & 88.8 & 88.8 & $88.8 / 8=x$ & 88.88 & 88.5 & 16 & Yemen 20010 \\
\hline & 17 & 7.3 & 8.7 & 6.6 & 7.3 & 6.6 & 7.7 & 8.7 & 8.0 & 6.6 & 9.6 & 7.3 & 7.3 & 6.9 & 7.7 & 7.3 & 10.6 & & 92.9 & 932 & 925 & 93.29 & 93.29 & 92.9 & 17 & Nigeria 75-1 \\
\hline & 18 & 0.9 & 3.2 & 1.9 & 25 & 1.3 & 1.3 & 10.5 & 32 & 22 & 11.1 & 5.5 & 1.9 & 29 & 2.9 & 25 & 132. & 7.7 & & 97.5 & 96.95 & $97.59-x$ & 97.59 & 97.2 & 18 & CHTib 07 \\
\hline & 19 & 22 & 3.8 & 0.6 & 2.5 & 1.3 & 2.5 & 9.7 & 3.2 & 22 & 10.3 & 5.5 & 1.9 & 29 & 29 & 25 & 12.4 & 7.3 & 2.5 & & 99.41 & 100.01 & 100.09 & 99.7 & 19 & CH Shaanis 2014 \\
\hline & 20 & 2.9 & 4.5 & 1.3 & 3.2 & 1.9 & 3.2 & 10.1 & 3.9 & 2.9 & 10.3 & 6.2 & 25 & 3.5 & 3.5 & 3.2 & 12.4 & 8.0 & 3.2 & 0.6 & & 99.49 & $99.4 s$ & 99.1 & 20 & CHHNZM 2014 \\
\hline & 21 & 22 & 3.8 & 0.6 & 25 & 1.3 & 2.5 & 9.7 & 3.2 & 22 & 10.3 & 5.5 & 1.9 & 29 & 29 & 25 & 12.4 & 7.3 & 25 & 0.0 & 0.6 & & 100.09 & 99.7 & 21 & CHBJ 2014 \\
\hline & 22 & 22 & 3.8 & 0.6 & 2.5 & 1.3 & 2.5 & 9.7 & 3.2 & 22 & 10.3 & 5.5 & 1.9 & 2.9 & 29 & 25 & 12.4 & 7.3 & 2.5 & 0.0 & 0.6 & 0.0 & & 99.7 & 22 & CHXYL 2013 \\
\hline & 23 & 2.5 & 4.2 & 0.9 & 2.9 & 1.6 & 2.9 & 10.1 & 3.5 & 25 & 10.7 & 5.9 & 22 & 3.2 & 3.2 & 29 & 12.8 & 7.6 & 2.9 & 0.3 & 0.9 & 0.3 & 0.3 & & 23 & CHXIlbex 2015 \\
\hline & & 1 & 2 & 3 & 4 & 5 & 6 & 7 & 8 & 9 & 10 & 11 & 12 & 13 & 14 & 15 & 16 & 17 & 18 & 19 & 20 & 21 & 22 & 23 & & \\
\hline
\end{tabular}

Figure 2. F gene nucleotide homology analysis.

\section{Evolutionary genetic analysis of the $\mathrm{F}$ gene}

Evolutionary genetic analysis was conducted on the F gene from 23 PPRV strains. The results showed that the F gene of the PPRV Xinjiang/Ibex/2015 strain was most similar to those of the China/XJYL/2013 and China/Shaanxi/2014 viral strains, suggesting that these genes may share a common origin, and that they belonged to the same branch, lineage IV, along with the Iraq_2002, Nepal_2009, and China/Tibet/07-1 strains (Figure 3).

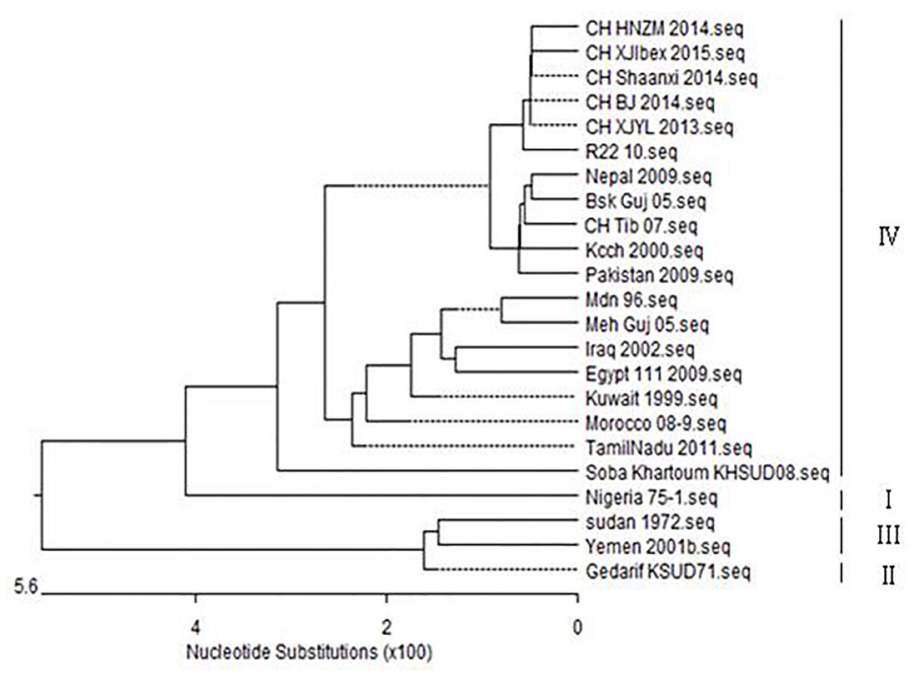

Figure 3. Phylogenetic analysis based on nucleotide sequences of the F gene. 


\section{DISCUSSION}

In the current study, PPRV infection was identified via RT-PCR amplification of the viral $\mathrm{F}$ gene from ibex samples collected in Xinjiang, China. For the first time, it was found that 38 ibexes (including young and adult ibexes) died within a 2-month period in 2015 from PPR in Xinjiang. Based on the 322-bp sequence of the F gene characterized in this study, a phylogenic tree was constructed based on similar sequences identified from GenBank. The phylogenetic analysis indicated that the F gene sequence from the Xinjiang/Ibex/2015 strain was in lineage IV along with PPRV strains from Asia and the Middle East. Moreover, the results showed that the PPRV detected from these ibexes shared a high-level of sequence homology with PPRV strains of the lineage IV type, exhibiting 94.4-99.7\% sequence identity at the nucleotide level, especially to strains isolated in China, which exhibited a higher sequence identity of 99.1-99.7\% (Figure 1).

In conclusion, for the first time it was found that ibexes in Xinjiang were infected with PPRV, and that the virus was in lineage IV. Meanwhile, these cases were found to be negative for foot and mouth disease, pasteurella, and streptococcus. The results of the current study add to the genetic resources available for PPR, provide a basis for further study of F protein biological functions, and provide meaningful information for future investigations into the molecular epidemiology of PPR in wild animals. Additionally, countries surrounding China, including India, Iran, and Pakistan are all areas severely affected by PPR, and will thus benefit from this information. Since the first discovery of PPR in Tibet in 2007, PPR continues to spread in China, reminding us to stay alert and strengthen PPR immunosurveillance in order to one day eradicate this disease.

\section{Conflicts of interest}

The authors declare no conflict of interest.

\section{ACKNOWLEDGMENTS}

Research supported by the National Science and Technology Pillar Program during the Twelfth Five-year Plan Period (\#2013BAD12B04). We thank Zheng Xueguang for his critical reading and comments on the manuscript.

\section{REFERENCES}

Albina E, Kwiatek O, Minet C, Lancelot R, et al. (2013). Peste des Petits Ruminants, the next eradicated animal disease? Vet. Microbiol. 165: 38-44. http://dx.doi.org/10.1016/j.vetmic.2012.12.013

Bailey D, Banyard A, Dash P, Ozkul A, et al. (2005). Full genome sequence of peste des petits ruminants virus, a member of the Morbillivirus genus. Virus Res. 110: 119-124. http://dx.doi.org/10.1016/j.virusres.2005.01.013

Dhar P, Sreenivasa BP, Barrett T, Corteyn M, et al. (2002). Recent epidemiology of peste des petits ruminants virus (PPRV). Vet. Microbiol. 88: 153-159. http://dx.doi.org/10.1016/S0378-1135(02)00102-5

Govindarajan R, Koteeswaran A, Venugopalan AT, Shyam G, et al. (1997). Isolation of pestes des petits ruminants virus from an outbreak in Indian buffalo (Bubalus bubalis). Vet. Rec. 141: 573-574. http://dx.doi.org/10.1136/vr.141.22.573

Haffar A, Libeau G, Moussa A, Cécile M, et al. (1999). The matrix protein gene sequence analysis reveals close relationship between peste des petits ruminants virus (PPRV) and dolphin morbillivirus. Virus Res. 64: 69-75. http:// dx.doi.org/10.1016/S0168-1702(99)00080-5

Jing B, Zhao YJ, Yuan Y and Liu B (2004). The research progress of small ruminants virus. Xi Mu Yu Shaou Yi 36: 40-43. 
Muthuchelvan D, Sanyal A, Sreenivasa BP, Saravanan P, et al. (2006). Analysis of the matrix protein gene sequence of the Asian lineage of peste-des-petits ruminants vaccine virus. Vet. Microbiol. 113: 83-87. http://dx.doi.org/10.1016/j. vetmic.2005.10.014

Özkul A, Akca Y, Alkan F, Barrett T, et al. (2002). Prevalence, distribution, and host range of Peste des petits ruminants virus, Turkey. Emerg. Infect. Dis. 8: 708-712. http://dx.doi.org/10.3201/eid0807.010471

Wang J, Wang M, Wang S, Liu Z, et al. (2015). Peste des petits ruminants virus in Heilongjiang province, China, 2014. Emerg. Infect. Dis. 21: 677-680. http://dx.doi.org/10.3201/eid2104.141627

Wang Z, Bao J, Wu X, Liu Y, et al. (2009). Peste des petits ruminants virus in Tibet, China. Emerg. Infect. Dis. 15: 299301. http://dx.doi.org/10.3201/eid1502.080817

Zhu XL, Zhang Q, Yang F, Dou YX, et al. (2009). Construction and expression of the eukaryotic expression vector with F gene of peste des petits ruminants virus. Chin. Vet. Sci. 39: 405-409. 